\title{
XXI Zjazd \\ Polskiego Towarzystwa Chirurgii Onkologicznej
}

Od 21 do 23 maja 2015 roku na terenie Międzynarodowych Targów Poznańskich odbywał się XXI Zjazd Polskiego Towarzystwa Chirurgii Onkologicznej. Tematem przewodnim spotkania było „Leczenie skojarzone raka piersi oraz postępy w chirurgii onkologicznej".

Uroczyste otwarcie Zjazdu rozpoczęło się od wystąpienia Przewodniczącego Komitetu Organizacyjnego dr. hab. Dawida Murawy, po którym głos zabrał Prezes PTChO prof. Piotr Rutkowski. Po wystąpieniach zaproszonych gości nadszedł czas na wręczenie tytułu Członka Honorowego PTChO prof. Maciejowi Krzakowskiemu, prof. Jerzemu Mi-

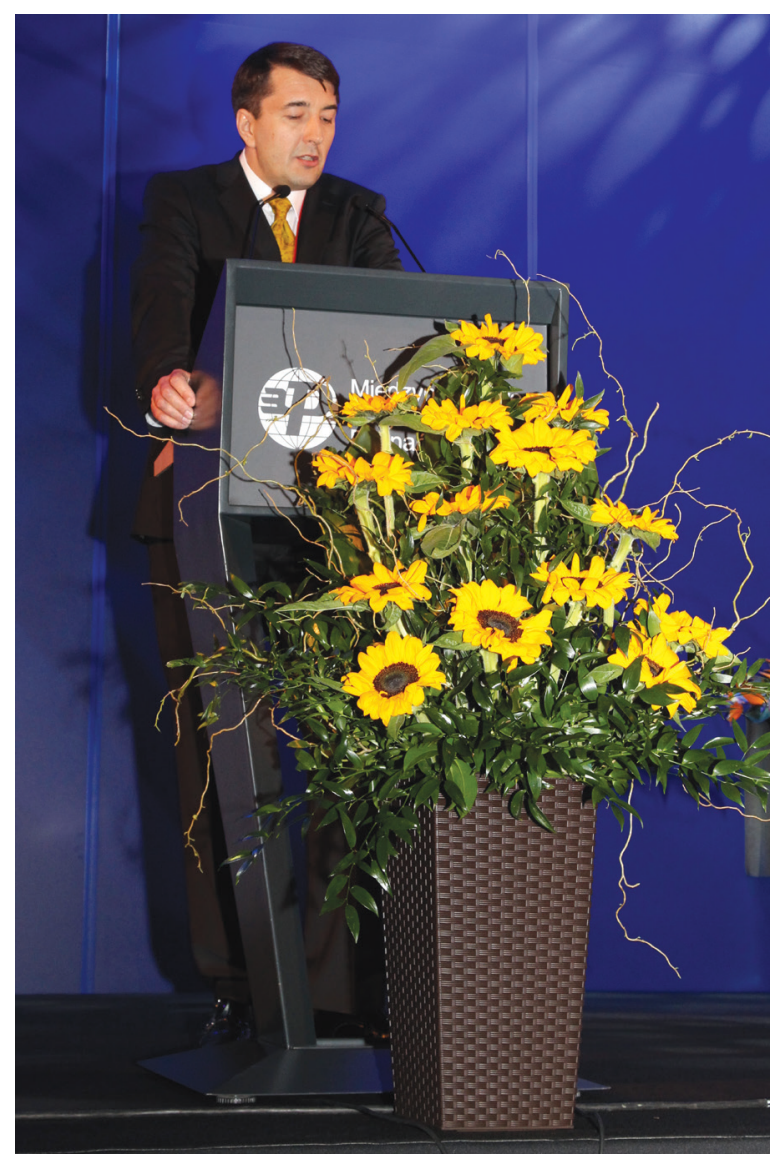

Wystąpienie przewodniczącego Komitetu Organizacyjnego Zjazdu dr. hab. Dawida Murawy tusiowi oraz prof. Marianowi Reinfussowi. Wręczone zostały również medale „Zasłużony dla PTChO”. Wykład im. Prof. Tadeusza Koszarowskiego pt:„Symbole i mity — spotkania z Tadeuszem Koszarowskim" wygłosił prof. Edward Towpik.

Pierwszy dzień Zjazdu rozpoczął się od spotkania z ekspertami i dyskusji na temat zakresu zabiegu w zlokalizowanym raku odbytnicy oraz leczenia mięsaków przestrzeni zaotrzewnowej. W trakcie spotkania Sekcji Węzła Wartowniczego zwrócono uwagę na problematykę limfadenektomii w przypadku przerzutu do jednego węzła wartowniczego w raku piersi oraz kontrowersji związanych z biopsją węzła wartowniczego u chorych na raka piersi, poddanych leczeniu neoadiuwantowemu. Następnie uczestnicy Zjazdu mogli wybrać jedną z sesji: satelitarną (czerniaki), plenarną (kontrola po leczeniu radykalnym wybranych nowotworów) oraz lunchową („Nie ma leczenia bezżywienia”). Podczas tej ostatniej przedstawiono nowe wytyczne leczenia żywieniowego oraz poruszono problem roli diety immunomodulującej. Kolejna sesja poświęcona była nowym technikom leczenia chorych z przerzutami do wątroby. Ciekawy wykład dotyczący elektrochemioterapii przerzutów raka jelita grubego do wątroby został przedstawiony przez jednego z wykładowców zagranicznych — prof. Ibrahima Edhemovica, prezesa Słoweńskiego Sektora Chirurgii Onkologicznej.

Po południu nadszedł czas na interaktywne debaty: 1) zaawansowane technologie wpływające na efektywność i bezpieczeństwo zabiegów kolorektalnych, 2) rola śródoperacyjnej radioterapii w leczeniu uzupełniającym po leczeniu miejscowym chorych na raka piersi (z udziałem prof. Marca Sutterlina z Mannheim), 3) rola chirurgii cytoredukcyjnej (R2) w leczeniu chorych z przerzutami raka jelita grubego do wątroby, 4) rola leczenia chirurgicznego w przerzutowym czerniaku oraz 5) skin sparing mastectomy - bezpieczeństwo onkologiczne a efekt kosmetyczny. Poza głównymi sesjami odbyły się dwie sesje prac oryginalnych: pierwsza, obejmująca zagadnienia związane z rakiem piersi, a druga - dotycząca różnych aspektów chirurgii onkologicznej. Ponadto podczas odrębnej sesji eksperci omówili najciekawsze doniesienia plakatowe. Część oficjalną pierwszego dnia Zjazdu zakończyło Walne Zgromadzenie Członków PTChO. Po obfitującym w wykłady i dyskusje dniu odbyło się 


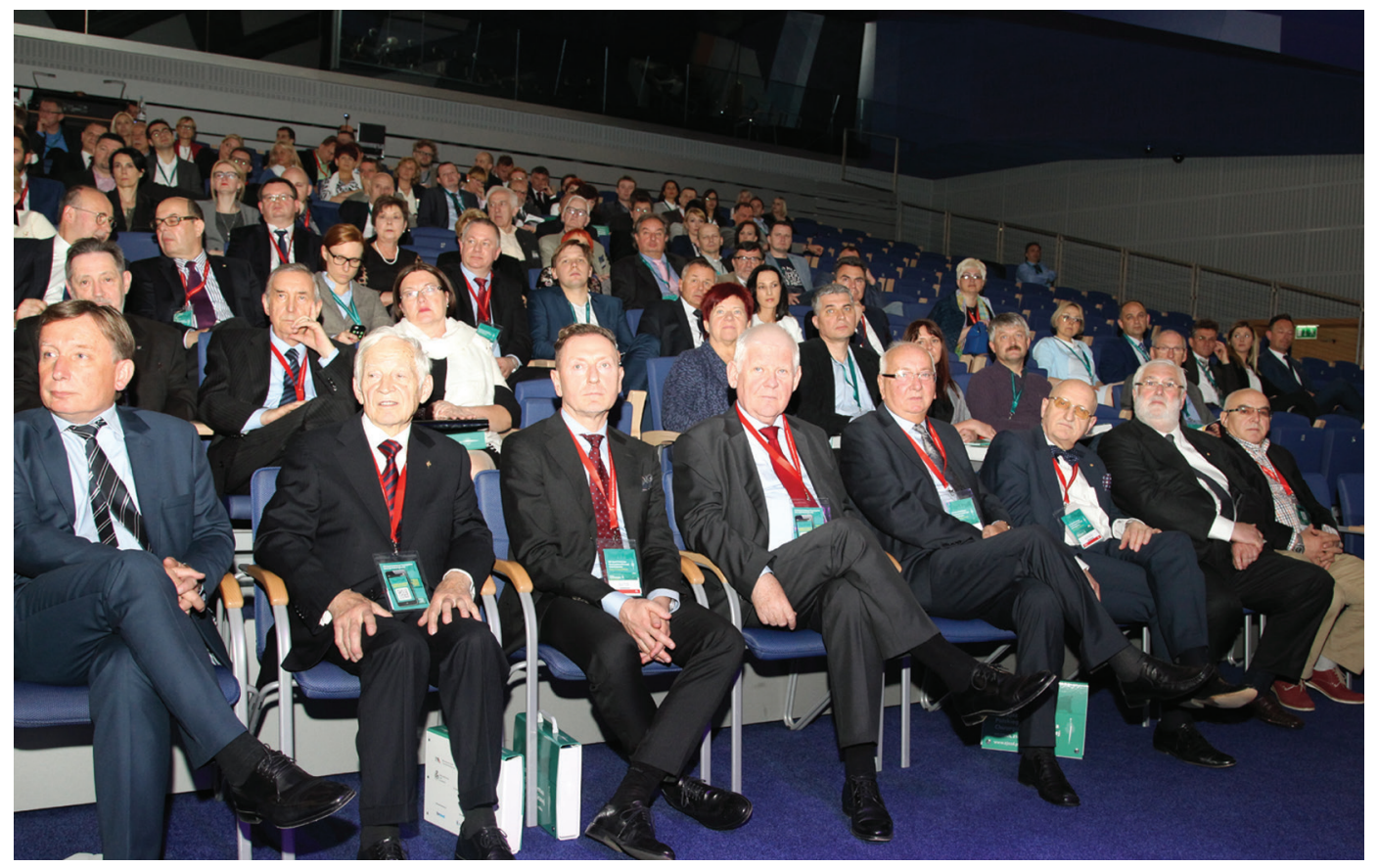

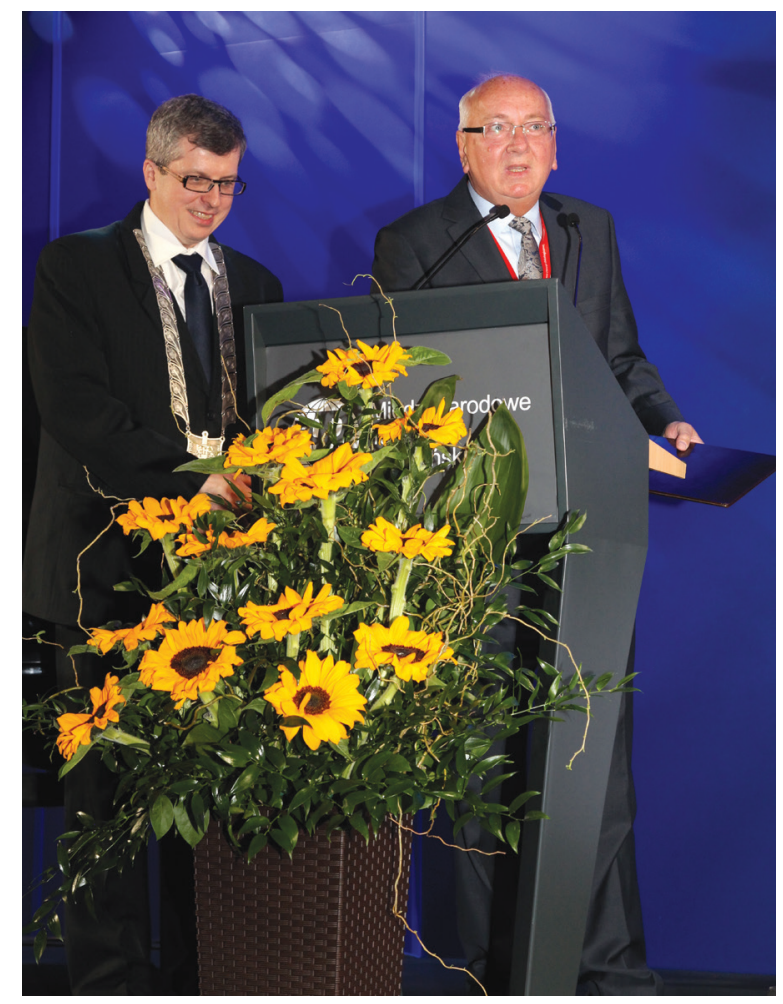

Prof. Jerzy Mituś odbiera dyplom Członka Honorowego PTChO z rąk Prezesa prof. Piotra Rutkowskiego

spotkanie towarzyskie w klubie Blow-Up Hall, które uświetnił występ zespołu „Żuki”.

Drugi dzień Zjazdu rozpoczęła sesja dotycząca ważnych problemów w leczeniu chorych na raka piersi oraz odbywająca się równocześnie sesja poświęcona leczeniu skojarzonemu. Podczas sesji specjalnej uczestnicy mieli okazję zapoznać się z prawidłową diagnostyką raka piersi, raka żołądka oraz czerniaka. O problemach związanych w rekonstrukcją piersi po radioterapii mówił dr Marek Budner z Bad Saarow, a cała sesja poświęcona była onkoplastyce i rekonstrukcji piersi. Znaczenie śródoperacyjnej radioterapii w chirurgii onkologicznej stanowiło tematykę kolejnej sesji. O możliwości zastosowania IORT w leczeniu chorych na raka piersi mówił m.in. prof. Felix Sedlmayer z Salzburga. Równolegle toczyła się sesja poświęcona leczeniu miejscowemu chorych na raka piersi. Zjazd zakończył i podsumował Prezes PTChO prof. Piotr Rutkowski, który przedstawił nagrodzone prezentacje ustne i plakatowe.

XXI Zjazdowi PTChO towarzyszyły również inne wydarzenia naukowe. Pierwszym z nich był zorganizowany po raz kolejny w Poznaniu kurs "Gastric cancer - Central and Eastern Europe Advanced Course" pod patronatem PTChO, Gruppo Italiano Ricerca Cancro Gastricco (GRICC), International Gastric Cancer Association (IGCA), Societa Italiana di Chirurgia Oncologica (SICO) oraz Europen Society Surgical Oncology (ESSO). Organizatorami tego kursu byli prof. Franco Roviello oraz dr hab. Dawid Murawa. W formie warsztatów omówiono najistotniejsze zagadnienia związane z leczeniem chorych na raka żołądka (diagnostyka, leczenie neoadiuwantowe, leczenie operacyjne oraz kontrola pooperacyjna). Elementem kursu była transmisja z sali operacyjnej — pokazowa resekcja żołądka wraz z limfadenektomią D3).

Kolejnym ważnym wydarzeniem była XXXII Konferencja Naukowo-Szkoleniowa „Postępowanie w zaawansowanych nowotworach górnego odcinka przewodu pokarmowego". 


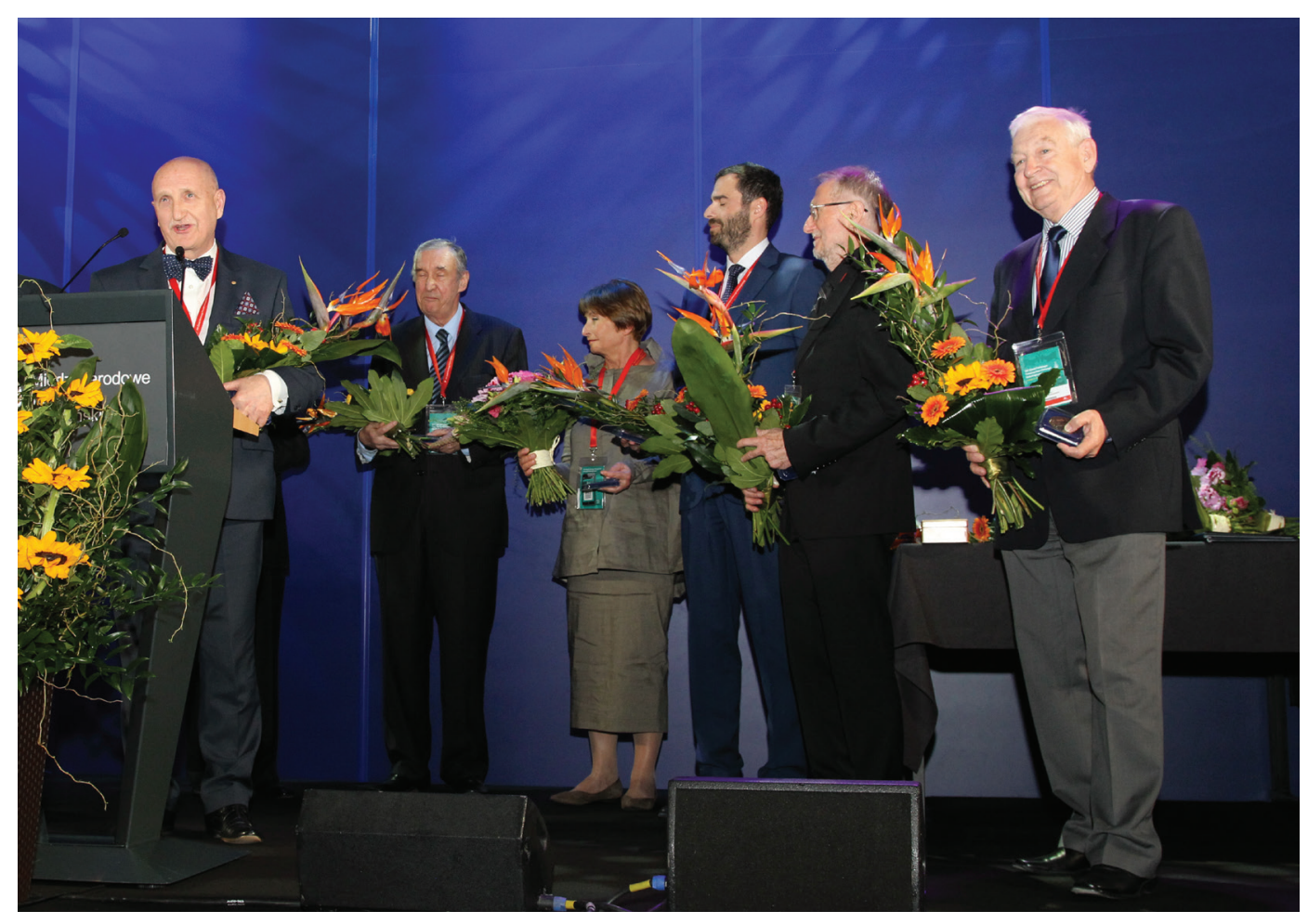

Osoby uhonorowane Medalem „Zasłużony dla PTChO”:

prof. Marek Krawczyk (przemawia), prof. Ireneusz Krasnodębski, dr Elżbieta Stachlewska-Nasfeter, dr Wojciech Wysocki, dr Włodzimierz Nowatorski i dr Wiesław Sosnowski

Dla studentów oraz lekarzy rozpoczynających pracę zawodową zorganizowano „Sesję młodych”, podczas której mogli zaprezentować opisy przypadków. Najciekawsze wystąpienia nagrodzono.

We współpracy z Polskim Stowarzyszeniem Pielęgniarek Onkologicznych zorganizowano także sesje dla pielęgniarek („Zespół terapeutyczny wobec pacjenta z chorobą nowotworową"); spotkanie podzielono na trzy bloki tematyczne: profilaktyka w onkologii, leczenie wspomagające oraz dylematy współczesnej onkologii.
Wszyscy specjalizujący się w chirurgii onkologicznej mogli wziąć udział w kursie wprowadzającym, tradycyjnie poprzedzającym Zjazd.

Podczas Zjazdu i wszystkich towarzyszących mu wydarzeń omawiano istotne problemy związane z chirurgią onkologiczną, a znakomity dobór prelegentów zagwarantował wysoki poziom merytoryczny. W Zjeździe uczestniczyło niemal 700 lekarzy reprezentujących wszystkie krajowe ośrodki onkologiczne.

\section{Dr med. Arkadiusz Spychała}

I Oddział Chirurgii Onkologicznej i Ogólnej

Wielkopolskie Centrum Onkologii

e-mail:spychala@me.com 